\title{
Intracavitary course of right coronary artery
}

\author{
L. J. Bouhuijzen (1) · J. J. Kardux · R. L. Braam
}

Published online: 8 April 2019

(C) The Author(s) 2019

A 64-year-old woman was referred to the cardiology department for evaluation of atypical chest pain. A cardiac computed tomography (CT) scan demonstrated a calcium score of zero and no coronary stenosis. As an incidental finding, the scan revealed an anomalous course of a $4-\mathrm{cm}$ segment of the right coronary artery (RCA) within the right atrium. The CT scan is shown in Fig. 1. No abnormalities were noted in the other coronary arteries and branches.

An intra-atrial or intracavitary course of the RCA is rare; the incidence is estimated at $0.09-0.1 \%$ [1]. Although this anomaly does not account for the patient's symptoms, it is of significance for various potential interventions. RCA injury may occur during pacemaker implantation, right heart catheterisation, electrophysiological studies and ablations [2]. Disruption can lead to myocardial ischaemia and leftto-right shunting. Furthermore, difficulties may arise during coronary artery bypass surgery with regard to vessel localisation or bypass grafting.

Conflict of interest L.J. Bouhuijzen, J.J. Kardux and R.L. Braam declare that they have no competing interests.
Open Access This article is distributed under the terms of the Creative Commons Attribution 4.0 International License (http://creativecommons.org/licenses/by/4.0/), which permits unrestricted use, distribution, and reproduction in any medium, provided you give appropriate credit to the original author(s) and the source, provide a link to the Creative Commons license, and indicate if changes were made.

\section{References}

1. Zalamea RM, Entrikin DW. Wannenburg et al. Anomalous intracavitary right coronary artery shown by cardiac CT: a potential hazard to be aware of before various interventions. JCardiovasc Comput Tomogr. 2009;3:57-61.

2. TovarE, BorsariA, Landa D, etal. Ventriculotomy repair during revascularization of intracavitary anterior descending coronary arteries. Ann Thorac Surg. 1997;64:1194-6.

\author{
L. J. Bouhuijzen, MD ( $\bowtie)$ \\ Department of Cardiology, Thoraxcentrum Twente, Medisch \\ Spectrum Twente, Enschede, The Netherlands \\ l.bouhuijzen@mst.nl \\ Lexbouhuijzen@gmail.com \\ J. J. Kardux, MD \\ Department of Radiology, Gelre Ziekenhuizen, Apeldoorn, \\ The Netherlands
}

R. L. Braam, MD, PhD

Department of Cardiology, Gelre Ziekenhuizen, Apeldoorn, The Netherlands 
Fig. 1a-c Intra-atrial course of the right coronary artery (RCA) using volume-rendered $3 \mathrm{D}$ reconstructions. a $\mathrm{Ar}$ row showing the RCA entering the right atrium $(R A)$; the right ventricle $(R V)$ is shown as well. b, c Arrows showing the RCA entering and exiting the RA. d Coronal view of the RCA, the arrow indicates the intra-atrial course
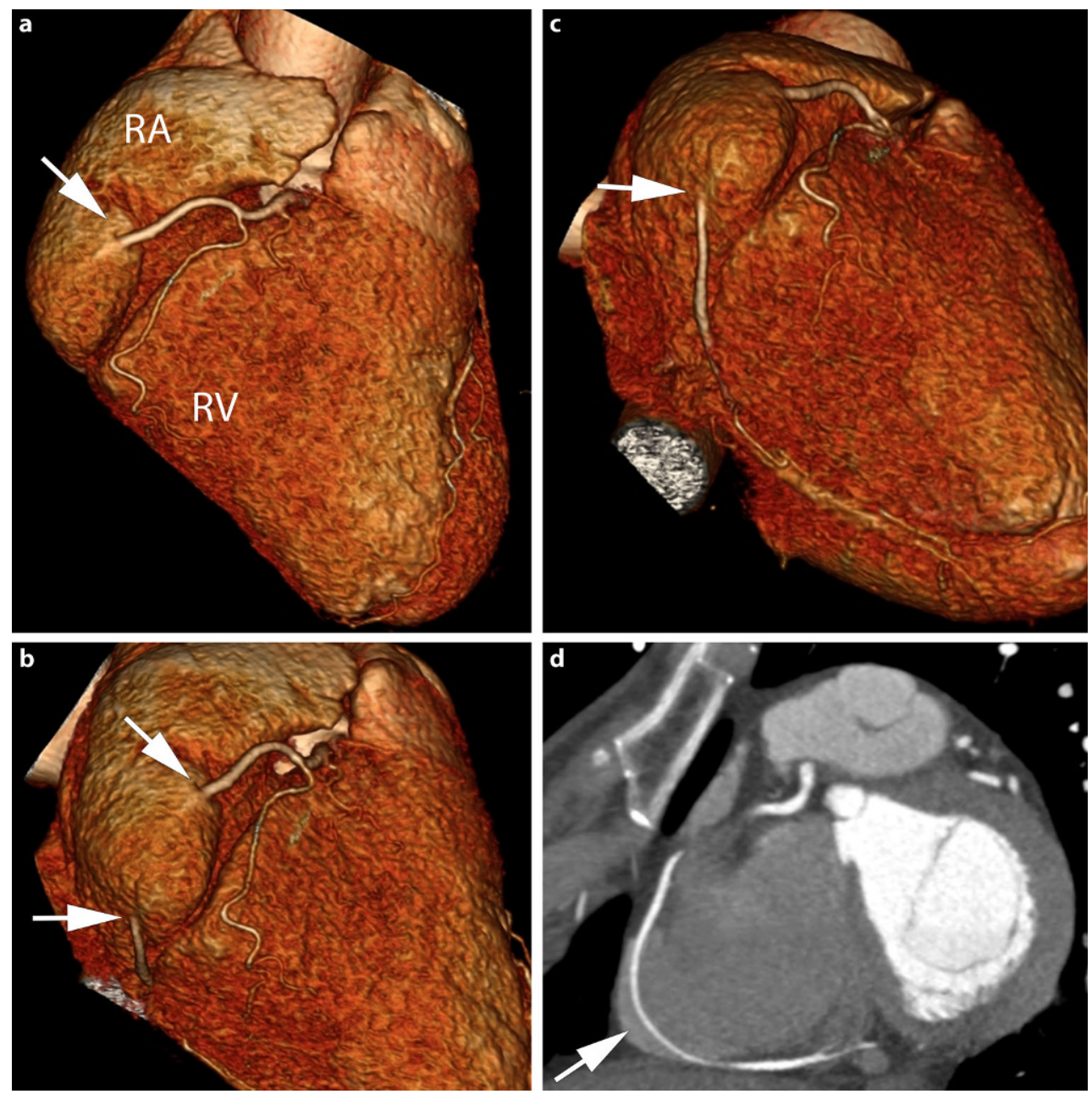